\title{
Direitos humanos e currículo transnacional: os desafios da licenciatura em história da Unilab
}

\author{
Human rights and transnational curriculum: \\ the challenges within a History degree course at Unilab
}

Edson Holanda Lima Barboza*

Silviana Fernandes Mariz ${ }^{\star *}$

\section{Resumo}

Este artigo analisa o processo de construção e de implementação do curso de Licenciatura em História da Universidade da Integração Internacional da Lusofonia Afro-Brasileira (Unilab) na cidade de Redenção, no Ceará. Foram analisados seus documentos oficiais, sobretudo o Projeto Pedagógico do Curso e resoluções do Conselho Nacional de Educação (CNE), e a prática docente dos autores. Demonstra-se como as diretrizes apontadas pela Resolução CNE/CP no 2/2015 possibilitaram ao curso atender ao perfil dos estudantes, jovens de áreas periféricas do Ceará e da Comunidade dos Países de Língua Portuguesa (CPLP), ao proporcionar educação superior pública e de qualidade para a formação de professores, privilegiando, a partir da autonomia curricular, as abordagens dos direitos humanos, da História da África e da diáspora africana.

Palavras-chave: direitos humanos; currículo; ensino de História.

\section{Abstract}

This article analyzes the building and implementing process of the History Degree course at the University of International Integration of Afro-Brazilian Lusophony (Unilab) in the city of Redenção, in Ceará. It were analyzed its Pedagogical Project of the Course, the resolutions of the National Council of Education and the teaching practice of the authors. It demonstrates as well how the guidelines issued by the National Council of Education through its Resolution $n^{\circ} 02 / 2015$ enabled the course which is tailored to young students from peripheral areas of Ceará and of the Commonwealth of PortugueseSpeaking Countries (CPLP) to offer a quality public higher education for teacher training towards the approaching on Human Rights and the History of Africa and its Diaspora, through curricular autonomy.

Keywords: human right; curriculum; History teaching.

\footnotetext{
* Universidade da Integração Internacional da Lusofonia Afro-Brasileira (Unilab), Redenção, CE, Brasil.edsonholanda@unilab.edu.br

** Universidade da Integração Internacional da Lusofonia Afro-Brasileira (Unilab), Redenção, CE, Brasil.silviana_mariz@unilab.edu.br
} 
Os direitos humanos só se tornam significativos quando ganham conteúdo político. (HUNT, 2009, p. 19).

Em seu já clássico $A$ invenção dos direitos humanos: uma história, a inglesa Lynn Hunt esmiúça o processo de gênese dos chamados "direitos humanos", desde a ocorrência das revoluções burguesas na Europa e na América, especificamente nos Estados Unidos, até os dias atuais (HUNT, 2009). Buscando entender como diferentes sujeitos históricos aderiram à defesa inconteste do que vai emergir em suas visões políticas como algo "autoevidente" (HUNT, 2009, p. 17), a historiadora postula, de modo enfático, a epígrafe, acima destacada, em antecipação ao que possivelmente explicaria a incorporação da defesa do que se entendia à época por "direitos humanos", por homens ${ }^{1}$ com diferentes lugares sociais e perspectivas de ação. Dito de outra forma: o que teria permitido a divulgação e certa popularização da ideia de "direitos humanos" entre mentes tão diversas foi certamente os seus significados políticos nela contida. Ainda de outro modo: isto significa dizer que, ao se defender "direitos humanos", necessariamente, se está no exercício de defesa de certos significados políticos que, desde as revoluções burguesas, então, contemplam necessariamente a defesa da emancipação humana por meio das garantias de suas liberdades, em particular das individuais.

Trazemos Hunt (2009) ao diálogo para com ela corroborar, no sentido de sublinhar, como tendo um significado político, a escolha tanto institucional quanto humana em desenvolvermos um currículo não hegemônico que promova o descentramento da Europa como epicentro único das formas de conhecer o mundo, aproximando-se de outras experiências e construções de sentido desenvolvidas por diferentes sociedades que não apenas aquelas representativas da Europa. Fazer isso é assumir uma escolha que é atravessada por uma opção política que privilegia, portanto, as experiências subalternizadas e marginalizadas pela tradição científica ocidental. Tomaz Tadeu da Silva, em seu já clássico Documentos de Identidade: uma introdução às teorias do currículo, nos ensina que:

o currículo é também uma questão de poder [...]. Selecionar é uma operação de poder. Privilegiar um tipo de conhecimento é uma operação de poder. Destacar, 
entre as múltiplas possibilidades, uma identidade ou subjetividade como sendo a ideal é uma operação de poder. (SILVA, 2010, p. 16).

E ao concedermos este significado político aos processos educativos, entendidos como direito humano básico e inegociável, problematizamos, em nossas práticas docentes na Universidade da Integração Internacional da Lusofonia Afro-Brasileira (Unilab), o ideal de universalidade tão evidenciada nas narrativas defensoras dos direitos humanos, genericamente visto como algo inato a todo o ser humano. Com isto, estamos dando corpo e voz específicos ao que geralmente se dilui em discursos difusos de mera retórica.

Este artigo, desse modo, analisa a opção pedagógica e epistemológica adotada na Unilab, em especial no curso de Licenciatura em História, pautada na adoção de um currículo referenciado nas experiências afrodiaspóricas e, portanto, centrado nas experiências e nos saberes construídos por diferentes sociedades não hegemônicas ${ }^{2}$.

ENSINO SUPERIOR NA UNILAB: INTERIORIZAÇÃO, INTERNACIONALIZAÇÃO, DIREITOS HUMANOS E SOCIAIS PARA JOVENS PERIFÉRICOS

A Unilab foi criada pela Lei ${ }^{\circ} 12.289 / 2010$, com a missão institucional de ofertar ensino superior para "formar recursos humanos para contribuir com a integração entre o Brasil e os demais países membros da [...] CPLP, especialmente os países africanos, bem como promover o desenvolvimento regional e o intercâmbio cultural, científico e educacional" (BRASIL, 2010a). Nesse sentido, percebe-se que a Unilab foi pensada para ser uma instituição de ensino superior pautada no binômio "interiorização - internacionalização", tendo como elo de embasamento ou de costura envolvendo esses dois eixos o ideal de integração: integração dos espaços nacionais periféricos dentro de uma geografia nacional das grandes universidades federais concentradas geralmente nas capitais de cada Estado; integração desses espaços tidos por periféricos com outras regiões do globo.

Com tantos aspectos, atribuições e finalidades singulares, e tendo tanto sido inaugurada em um momento de mudanças, ainda que conjunturais para a sociedade brasileira, quanto tendo, ela mesma, consagrado um novo mode- 
lo de universidade para o Brasil, mesmo que apenas no campo simbólico ${ }^{3}$, é inegável a relevância de seu importante papel de instituição de ensino superior no país. Tão inegável que, em sua primeira década de existência, a Unilab se consolidou como uma Instituição Federal de Ensino Superior (IFES) multicampi, com três campi em pleno funcionamento em duas unidades federativas do país: dois campi no Ceará, estado da sede da Unilab, localizados no município de Redenção, além de uma unidade acadêmica, situada em Acarape; e um campus na Bahia, localizado no município de São Francisco do Conde.

Estando, portanto, sua sede localizada na macrorregião do Maciço de Baturité, distante $72 \mathrm{~km}$ da capital cearense, a Unilab, além de incluir em suas finalidades e objetivos a integração entre a comunidade brasileira e lusoafricana como forma de combater o racismo e promover o entendimento e a colaboração por meio de trocas e contatos científicos, ou seja, a integração de diferentes grupos étnicos, na condição de instituição de ensino superior, também tem assumido como compromisso de cunho social, e não meramente científico, a elevação dos índices de desenvolvimento humano na região onde se encontra situada e, consequentemente, a suplantação de seus déficits socioeconômicos.

Compondo o esforço de interiorização do ensino superior no Brasil, a internacionalização destaca-se como outro desafio da Unilab, especialmente no contexto de solidariedade e integração internacional com os membros da Comunidade dos Países de Língua Portuguesa (CPLP) em Angola, Cabo-Verde, Guiné-Bissau, São Tomé e Príncipe e Moçambique, situados na África, e Timor-Leste, países que compartilharam conosco a experiência colonial da dominação portuguesa e suas nefastas heranças: racismo, patriarcado, homofobia e outras formas de dominação e subalternidade.

Ao acolher e beneficiar estudantes brasileiros, africanos e timorenses na perspectiva de promover o intercâmbio de saberes e o desenvolvimento sustentável, o governo e a sociedade brasileiros estariam, assim, de algum modo, promovendo uma espécie de ressarcimento ou compensação aos negros da África lusófona pelos danos materiais e prejuízos humanos incalculáveis provocados pelo tráfico e escravidão que lhes foram impostos.

Assim, a Unilab, como ação do governo brasileiro no campo da educação, cumpriria o papel de garantir a oferta de um direito social fundamental, em consonância com o proposto na Declaração Universal dos Direitos Humanos: 
"cada indivíduo e cada órgão da sociedade, tendo sempre em mente esta Declaração, se esforce, através do ensino e da educação, por promover o respeito a esses direitos e liberdades, e, pela adoção de medidas progressivas de caráter nacional e internacional" (ONU, 1948, p. 4).

Com esse conjunto de desafios, em 25 de maio de 2011, a Unilab entrou em funcionamento. Em fevereiro de 2020, mês de conclusão do semestre 2019.2, contava com 4.619 estudantes (Unilab, 2019), sendo 3.463 brasileiros e 1.156 internacionais matriculados em 24 cursos de graduação que abrangem diferentes áreas do conhecimento. Nesse cenário, encontra-se o curso de Licenciatura em História, vinculado ao Instituto de Humanidades, no Estado do Ceará, com 192 estudantes matriculados, 83 egressos e 38 que estão em processo para se formar.

Quanto ao perfil discente do curso, temos predominantemente um público feminino, negro e nacional. Entre esses estudantes de origem majoritariamente nacional, $90 \%$ são de jovens oriundos da região do próprio Maciço

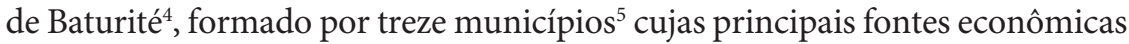
são as próprias administrações municipais, responsáveis pela oferta de emprego nos setores de educação e saúde, principalmente, caracterizando-se como municípios marcadamente vulneráveis do ponto de vista socioeconômico, dependentes dos investimentos públicos para a manutenção de suas populações ${ }^{6}$. Os estudantes nacionais são selecionados para o $1^{\circ}$ ciclo do Bacharelado em Humanidades (BHU) ${ }^{7}$ por meio do Sistema de Seleção Unificada (SiSU) e, após a conclusão do BHU, são submetidos a uma seleção interna utilizando o Índice de Rendimento Acadêmico (IDE) para definir a classificação às 40 vagas ofertadas semestralmente para o curso de História ( $2^{\circ}$ ciclo), sendo disponibilizadas 20 para nacionais e 20 para estudantes internacionais da CPLP.

É importante destacar que a Unilab reserva até $50 \%$ de suas vagas, na graduação, a candidatos dos países membros da CPLP, que consistem em jovens de diferentes regiões em seus países, o que nos traz uma imensa diversidade cultural que se expressa em suas línguas, práticas religiosas e, principalmente, no arcabouço de conhecimentos por eles apresentado, sendo que o ingresso dos discentes internacionais na Unilab tem se dado por meio do Processo Seletivo de Estudantes Estrangeiros (PSEE) ${ }^{8}$.

Apesar da diversidade em nosso corpo discente internacional, é preciso registrar as limitações do próprio processo seletivo que ocorre em parceria com 
as embaixadas brasileiras nos referidos países da CPLP. Como se sabe, a localização desse equipamento diplomático se concentra nas grandes cidades, geralmente nas capitais, o que muitas vezes se constitui em impeditivo para que jovens de áreas mais distantes participem. Desse modo, o perfil de parte de nossos estudantes africanos, ainda que vulnerável do ponto de vista socioeconômico, é, marcadamente, de origem urbana, oriundo de famílias com níveis significativos de escolarização e pertencentes às classes médias locais, aclimatados ao universo da educação formal, valendo destacar que muitos são adeptos do islamismo ou do cristianismo de viés evangélico neopentecostal.

Considerando os cenários nacional e internacional, a Unilab representa um importante marco para esses jovens, historicamente desassistidos por seus respectivos Estados, sem acesso aos direitos sociais, entre eles, o direito à educação. Sem exagero, é possível afirmar que, indiretamente, a Unilab, em decorrência da oferta de serviços internos como atendimento básico de saúde e restaurante universitário aos seus estudantes, representa, na prática, para muitos, residentes no Maciço de Baturité, segurança alimentar - nutricional e de saúde. A partir daí, dá-se acesso a um amplo repertório de conquistas no sentido de afirmar a cidadania desses jovens, até então, por eles mesmos, desconhecida.

Cabe assinalar que a Unilab, visando a sua afirmação como uma universidade voltada para o atendimento dos grupos sociais não hegemônicos, providenciou desde sua criação à adesão ao Plano Nacional de Assistência Estudantil (Pnaes) $)^{9}$ e a criação de uma Pró-Reitoria específica que se destinasse às demandas estudantis - a Pró-Reitoria de Políticas Afirmativas e Estudantis (Propae), responsável por gerir os recursos advindos do Pnaes, entre outros oriundos do próprio fundo orçamentário da universidade.

Apesar de haver observações críticas (Sales et al., 2019), com algumas das quais concordamos, principalmente quanto à forma como a expansão universitária ocorreu, desde 2007, no Brasil sob os auspícios da Reestruturação e Expansão das Universidades Federais (Reuni) ${ }^{10}$, cabe, no entanto, destacar os esforços positivos envidados pelos governos trabalhistas no Brasil no sentido de assegurar, ainda que minimamente, a exequibilidade dessas políticas. Um exemplo evidente é o Pnaes, que foi instituído em 2010 por decreto aprovado pelo então presidente Luíz Inácio Lula da Silva, e tem cumprido com a finalidade de amparar financeiramente estudantes vulneráveis do ponto de vista 
socioeconômico e, assim, assegurar a sua permanência na universidade, evitando evasões, sobretudo, em cursos que carecem de prestígio e valorização na forma de status conferido e (re)posicionamento social por meio de ofertas de trabalho vantajosas do ponto de vista financeiro (BRASIL, 2010c).

Em grande medida, é graças ao Pnaes que muitos jovens, oriundos de grupos sociais historicamente marginalizados no Brasil, têm conseguido se manter nas universidades. Se o Exame Nacional do Ensino Médio (Enem), pela aplicação dos diversos estratos de cotas sociais e raciais, tem permitido o acesso dessas populações não hegemônicas às universidades públicas federais brasileiras, o Pnaes tem permitido a sua permanência. No nosso entendimento, trata-se, sim, de duas políticas públicas voltadas para o avanço da afirmação dos direitos humanos no Brasil. Na Unilab, é o Pnaes que, em larga medida, tem assegurado também a permanência de estudantes indígenas e quilombolas, atendidos em seus cursos de graduação, incluindo o curso de Licenciatura em História.

Com isto, reafirmamos a orientação que a Unilab e, consequentemente, seus cursos de graduação, a exemplo da Licenciatura em História, desde sua criação, possuem características de um projeto de "universidade popular"11, entre as quais:

a) epistemologicamente, pela diversidade de vozes, saberes e práticas culturais, fundamentada numa racionalidade contra-hegemônica e não instrumental e objetivando um sentido amplo de emancipação/humanização do sujeito; b) metodologicamente, pela valorização dos saberes populares e coletivos, abordados numa ampla e constante inter-relação e pela inclusão das classes populares, com base em princípios de uma educação popular (SILVA, 2018, p. 119).

É, portanto, a Unilab um projeto em construção de universidade popular por se distinguir epistemologicamente e metodologicamente dos modelos tradicionais adotados largamente em outras instituições de ensino superior pelo Brasil afora. Como síntese desses eixos epistemológico e metodológico, analisaremos a seguir como essa diversidade de vozes, saberes e práticas culturais, fundamentada numa racionalidade contra-hegemônica tem se expressado especificamente no projeto político-pedagógico da Unilab e do curso de Licenciatura em História, em particular. 


\section{O BACHARELAdo EM Humanidades (BHU) - PRIMEIRO CICLO DE FORMAÇÃO: DIREITOS HUMANOS E INTERDISCIPLINARIDADE}

No mesmo ano em que a Unilab entrou em funcionamento, a Câmara de Educação Superior (CES) do Conselho Nacional de Educação (CNE) homologou, em 11 de julho de 2011, o Parecer CNE/CES n 266/2011 (Brasil, 2011), que aprovou os "Referenciais Orientadores para os Bacharelados Interdisciplinares e Similares das Universidades Federais", tendo como parâmetro a experiência bem sucedida da Universidade Federal do ABC (Ufabc).

Entre as argumentações que justificaram o surgimento dos bacharelados interdisciplinares estava o combate à evasão nos cursos de graduação, considerando que o egresso do ensino médio ao escolher um curso superior no SiSU não teria dimensão do currículo do curso escolhido e de sua área de atuação profissional, realizando tal descoberta somente ao frequentar o primeiro ano de graduação, quando, nos casos de falta de identificação, acabam abandonando a universidade. Outra argumentação seria a necessidade de flexibilizar o currículo da graduação, proporcionando uma formação mais ampla, indo além de uma área de conhecimento, ou disciplina, em específico.

Em diálogo com os debates em trâmite no cenário nacional, em 2012, durante o segundo ano de funcionamento da Unilab, os docentes com formação em ciências humanas tiveram a iniciativa de propor um curso de graduação interdisciplinar em humanidades, com direito à diplomação e duração de três anos, surgindo, assim, o Bacharelado em Humanidades (BHU). Atualmente, os cerca de 85 docentes lotados no Instituto de Humanidades ${ }^{12}$ ministram componentes curriculares no BHU e têm formação variada em Ciências Humanas: Antropologia, Educação, História, Filosofia, Sociologia, entre outras. A diversidade na composição do corpo docente do $1^{\circ}$ ciclo é um elemento importante que permite ao estudante o contato com múltiplas abordagens de modo interdisciplinar desde o início de sua formação.

Ao concluir o chamado $1^{\circ}$ ciclo, os egressos podem optar por um $2^{\circ}$ ciclo de graduação em áreas específicas: Licenciaturas em História, Sociologia ou Pedagogia e um Bacharelado em Antropologia. Parte da estrutura curricular do Bacharelado em Humanidades é comum aos cursos do $2^{\circ}$ ciclo, possibilitando que a duração total do percurso formativo nos dois ciclos tenha o tempo mínimo de 5 anos. $^{13}$ 
Entre os componentes curriculares comuns ao processo formativo dos $1^{\circ}$ e $2^{\circ}$ ciclos, merece destaque "Sociedades, Diferenças e Direitos Humanos nos Espaços Lusófonos/60h” (SDDH), ofertada, logo no primeiro semestre, com a finalidade de possibilitar aos estudantes brasileiros e africanos uma compreensão crítica dos processos de dominação estendidos pelos países europeus no contexto da colonização dos povos na América e na África.

As turmas de SDDH, ordinariamente, são formadas por uma média de 30 a 40 estudantes. De modo geral, as aulas iniciam em diálogo com o componente curricular "Inserção à Vida Universitária/15h ", ou seja, começamos sempre a partir do cotidiano na Unilab, lugar que será, pelos anos seguintes, o espaço de trocas, conexões e construção de conhecimento, tendo por base perspectivas teóricas referenciadas nas experiências afrodiaspóricas, ainda que sejam incluídas discussões e leituras que dialoguem com bibliografias atualmente tidas por "clássicas" ou "tradicionais".

No caso específico de SDDH, a bibliografia da disciplina vem pré-definida em sua ementa cuja variação vai de leituras clássicas como O povo brasileiro: a formação e o sentido de Brasil, de Darci Ribeiro (2005), até produções mais recentes advindas de intelectuais egressos do movimento negro brasileiro e/ou internacional, como é o caso de Sueli Carneiro (2011) em sua obra Racismo, sexismo e desigualdade no Brasil e de Kagenbele Munanga (2012) em Negritude: usos e sentidos. No entanto, na prática, sempre é convencionado pelo coletivo de professores a admissão de leituras-extra, incorporadas à disciplina na forma de "bibliografia suplementar". As leituras-extra geralmente se destinam às apresentações, individuais e/ou coletivas, que são cobradas dos estudantes em seu processo avaliativo.

As temáticas exploradas em SDDH também estão definidas em sua ementa:

\section{Sociedades, Diferenças e Direitos Humanos nos Espaços Lusófonos (60h)}

Ementa: Temporalidades do processo colonial nos países de língua portuguesa (práticas, trocas e conflitos culturais - ocupações e resistências). Movimento Pan-africanista, Negritude; Relações étnico-raciais e racismo; Movimento Negro e Indígena no Brasil e as políticas de ação afirmativa. Gênero, sexualidade. Movimentos Feministas e LGBTT. Tolerância religiosa. Direitos Humanos. Diferenças e Desigualdades. Cultura afro-brasileira. (Unilab, 2018, p. 63). 
Os conteúdos de SDDH contemplam as "Diretrizes nacionais para educação em direitos humanos" a partir do contexto dos países lusófonos e outras legislações educacionais brasileiras (BRASIL, 2012) ${ }^{14}$. Da ementa acima reproduzida, e com base empírico-analítica em nossas experiências e práticas docentes com a referida disciplina, é possível afirmar que o seu conjunto temático como um todo produz efeitos de interesse nos estudantes que, por razões diversas, se sentem impelidos a participar das discussões. Particularmente, acreditamos que a presença dos estudantes africanos em sala de aula enseja maiores questionamentos que não raramente são responsáveis por debates ricos sobre como a colonização portuguesa produziu resultados, ao mesmo tempo, tão diferentes e tão assemelhados em territórios separados por um oceano tão largo como é o Atlântico. Dos conteúdos que tocam tanto estudantes brasileiros quanto africanos, alguns são responsáveis por produzir debates mais sensíveis e que, portanto, exigem mais cuidados na escuta e no diálogo, como: "gênero e sexualidade"; "movimentos feministas e LGBTT"; "tolerância religiosa"; e "direitos humanos".

Nas aulas de SDDH, observamos que os temas "gêneros e sexualidades" e "movimentos feministas e LGBTT" impactam diferentemente discentes brasileiros e africanos. Enquanto entre os brasileiros, devido à presença de jovens autodeclarados LGBTQI+, consistem em temáticas que lhes fazem refletir sempre em termos da urgência em avançar as políticas públicas de atendimento e de garantia de seus direitos humanos, fazendo que, por vezes, não tenham "paciência com apenas debates teóricos"; para os estudantes africanos, por sua vez, essa temática, de início, não raro implica em negação não apenas do debate em si, mas da própria existência de pessoas LGBTQI+ na África. Daí, a introdução, como leitura suplementar, do artigo "Raízes históricas da homossexualidade no Atlântico lusófono negro" (MOTT, 2005). Por outro lado, o debate sobre a existência ou ausência de feminismos na África também é outro ponto de embates e impasses. Entre parte dos estudantes africanos, a ideia de que "mulher africana feminista" é "mulher mentalmente colonizada" não raro é manifestada, nas primeiras discussões, em tom tão assertivo que parece sugerir a dispensa de qualquer reflexão crítica. Por essa razão, é recorrente a inclusão, na forma suplementar, de algum texto de Chimamanda, geralmente, Sejamos todos feministas (ADICHIE, 2015).

Ainda baseados em nossa experiência docente ministrando a componen- 
te SDDH, percebemos também que, se nas temáticas relacionadas a gêneros e sexualidades, usualmente, somos nós, docentes e estudantes brasileiros, que levamos inquietações aos estudantes africanos, na abordagem das temáticas de "tolerância religiosa" e "direitos humanos", por outro lado, são os estudantes africanos que nos trazem inquietações. O porquê da negação da religiosidade na construção dos Estados nacionais e, portanto, das razões para a completa laicidade das sociedades capitalistas ocidentais são apontados por eles como importantes questões norteadoras de acalorados debates sobre a relação entre direitos humanos e religiosidade cuja suposta incompatibilidade lhes parece ser artificial e fruto do colonialismo europeu tardio. Por tudo isso, "tolerância religiosa" e "direitos humanos" são temáticas que, invariavelmente, também se abrem para a ampliação de leituras, fazendo-nos incluir os textos de Santos (2013) e de Mbaya (1997), em que ambos contestam a existência dos direitos humanos como linguagem da dignidade humana acantonada como discurso universal e generalista que ignora a diversidade de culturas no mundo, em especial no continente africano.

Nesse contexto de análise de SDDH, lembramos o que Sacristan e Gomez nos dizem sobre os documentos oficiais curriculares como "expectativas curriculares" que:

por si mesmas não são o currículo real. Possuem, no entanto, diferentes graus de aproximação ao que é a prática curricular. São como fotos lisas de um processo. A análise do livro-texto, por exemplo, nos aproxima mais da realidade educativa do que os documentos oficiais que regulam e promovem o currículo. Os planos reais dos/as professores/as nos aproximariam mais do que os livros-texto. (...). Documentos, textos, planos e tarefas são as 'fotos fixas' aproximadas de um processo que as liga. De certa forma, refletem o currículo, mas o estudo e a compreensão deste devem fixar-se no processo entre as fotos. (SACRISTAN; GOMEZ, 1998, p. 138).

Com isso, os autores entendem que os documentos oficiais são apenas pontos de partida na investigação curricular, devendo o processo educativo ser captado a partir de diferentes representações curriculares que, necessariamente, incluem os próprios documentos oficiais curriculares, no nosso caso o Projeto Pedagógico de Curso (PPC), os livros-texto, os guias-didáticos ou materiais diversos consumidos pelos professores/as e alunos/as, as programações e 
os planos de ensino produzidos no âmbito das unidades de ensino, o conjunto de tarefas de aprendizagem de em que os/as alunos/as extraem a experiência educativa real e, por fim, os exames e as avaliações que os/as professores/as exigem dos estudantes (Sacristan; Gomez, 1998). Somente por essas representações é que é possível termos uma visão mais aprofundada do processo curricular e, por esse motivo, passamos agora aos espaços “entre-fotos” de SDDH.

As aulas de SDDH, geralmente, ocorrem num formato de roda de conversa, fomentadas por uma temática-geradora, nos termos de Paulo Freire (2016); ou seja, para cada "aula", a turma é convidada a dialogar, a partir de um texto previamente indicado, sobre determinado assunto que irá gerar as discussões e a troca de ideias. A indicação da temática-geradora acompanha tanto a ementa da disciplina, representação oficial tangível do nosso currículo, quanto a própria dinâmica da turma e dela é dependente para se mover.

Um encontro norteado pela temática do racismo pode conduzir a problematizações e questionamentos acerca da dominação masculina, convencionalmente chamada pelos estudantes de machismo, sendo que, ao nos movermos para ela num encontro seguinte, podem ser abordadas especificamente as formas de dominação masculina em relação às mulheres indígenas e africanas. Nesse cenário, com a turma construindo o diálogo numa perspectiva histórica, é possível debatermos sobre como esses processos passaram a se dar na América e/ou na África desde a colonização ibérica, bem como se as sociedades indígenas e africanas pré-coloniais já admitiam práticas de controle e de dominação feminina. Ocorrendo tal desencadeamento de temáticas e debates, é certo que, no encontro seguinte, retornemos à temática inicial, de abertura da disciplina, sobre a ocupação da América pelos portugueses. De modo que, no caso de SDDH, entendemos a sua ementa não como caminho linear e progressivo. Na prática, ela se assemelha muito mais a um círculo epistemológico no qual as ideias ganham circularidade de acordo com a dinâmica instituída pela própria turma.

Quanto à avaliação da turma, ela é entendida como um processo que deve ser constante, buscando identificar nos estudantes o quanto conseguiram avançar na aprendizagem a partir das discussões ocorridas em sala de aula. No entanto, por mais que os procedimentos avaliativos sejam adaptados para fins de aproximação com a realidade e com o histórico de escolarização dos estudantes, infelizmente, a imposição institucional para atribuição de notas, esca- 
lonadas de zero a dez, como forma final de julgamento do trabalho discente termina por estimular tensões. Não raras vezes, algum estudante não apenas questiona a nota - o que geralmente também questionamos, pois duvidamos se realmente é possível sumarizar todo o trabalho discente de um semestre letivo inteiro em um número -, mas também questiona os procedimentos avaliativos como constituintes do processo educativo. Aqui, a proposta de aplicação de um currículo referenciado nas experiências afrodiaspóricas ou decoloniais, por vezes, é confundida pelos estudantes com o abandono do rigor acadêmico, visto como "expressão da racionalidade europeia".

Outros, provavelmente em razão de sua escolarização básica frágil, insistem em entender uma aula como sendo concebível unicamente no formato tradicional, ou seja, cadeiras dispostas linearmente, em fileiras, com o professor posicionado entre a turma e a lousa, lecionando por meio de um monólogo expositivo. Esse modelo de educação bancária, tão questionado por Freire (2016), ainda é adotado como sendo o formato de aula recorrente também nas universidades, sobretudo por elas serem vistas como lugares de seriedade e sisudez, onde não caberiam mudanças ao tradicionalmente executado. Quando esse modelo não é acionado, é comum algum estudante acreditar que não está ocorrendo "aula de verdade", pois seu entendimento do que é uma "aula de verdade" se restringe apenas ao que Freire (2016) chamou de "modelo bancário".

A ideia de que ser verdadeiramente não hegemônico, ou contra-hegemônico ${ }^{15}$, muitas vezes comporta também, na visão de alguns estudantes, a defesa da completa abolição de todas as formas de averiguação de aproveitamento, ou rendimento, acadêmico do estudante em relação aos conteúdos processados em sala de aula, começando pelo registro da frequência. Não raro, presenciamos estudantes que defendem, por exemplo, a sua ausência física da sala de aula como forma de superar os tradicionalismos pedagógicos e de se instituir práticas curriculares populares, sem que isso implique em sua reprovação por falta.

Tais situações de desentendimento nos servem como lembrete de que a Unilab, de fato, em inúmeros aspectos, permanece similar a outras universidades federais brasileiras, por sermos uma instituição superior de ensino financiada com recurso público e, portanto, submetida aos órgãos de fiscalização e regulação do Poder Executivo Federal. Esses são instrumentos de controle que impõem limites restritivos à autonomia universitária e às nossas práticas docentes cujas ações pedagógicas não podem ocorrer ao sabor exclusivo de 
nossas vontades. No entanto, insistimos em acreditar que mais resistimos do que reproduzimos, a partir do momento em que mantemos o compromisso com a concepção epistemológica subjacente ao projeto pedagógico da universidade e do curso, e, como diriam Sacristan e Gomez (1998), a resistência está exatamente na dimensão prática.

\section{A Licenciatura em História na Unilab, Ceará: EM BUSCA DE UM CURRÍCULO TRANSNACIONAL}

Em 2014, no terceiro ano de funcionamento da Unilab e após certo acúmulo na composição de seu corpo docente, foi dado início à concretização da primeira onda de expansão da universidade, cujo plano previa a implantação de cursos de licenciatura em alguns de seus institutos. O processo de construção do curso de Licenciatura em História da Unilab obedeceu a todos os princípios pedagógicos e institucionais definidos para a própria universidade, ou seja, deveria ser um curso que atendesse aos objetivos de interiorização, mas também os de internacionalização ${ }^{16}$. Desse modo, o ponto de partida foi assegurar que o curso se caracterizasse como sendo uma das opções de $2^{\circ}$ ciclo formativo dos estudantes egressos do Bacharelado em Humanidades (BHU), em funcionamento desde 2012.

Em 2015, com 3 anos após o ingresso da primeira turma do BHU, os egressos do $1^{\circ}$ ciclo começaram a colar grau, portanto, era necessário que os cursos de $2^{\circ}$ ciclo estivessem estruturados para receber a demanda. Nesse contexto, o curso de Licenciatura em História já estava pronto para admitir seus primeiros discentes, com seu corpo docente em quantidade mínima necessária ao seu funcionamento, bem como o seu PPC definido. O PPC de História consolidou-se em 2016, período de reformulação curricular das licenciaturas da Unilab, acompanhando os termos da Resolução CNE/CP no 2/2015, que estabeleceu as diretrizes para a formação de professores; contudo, por ser um curso de $2^{\circ}$ ciclo e integrado ao BHU, foram necessários alguns ajustes.

Quanto ao tempo mínimo de integralização curricular, o artigo $13, \S 1^{\circ}$, da Resolução CNE/CP no 2/2015, aponta a obrigatoriedade às licenciaturas de, no mínimo, 3.200 horas distribuídas em 8 semestres (4 anos) (BRASIL, 2015). Já o artigo 12 do mesmo regramento descreve os três Núcleos que constituem o curso de formação inicial de professores, a saber: I - "Formação geral, áreas 
específicas e interdisciplinares, e do campo educacional"; II - "Estudos das áreas de atuação profissional"; e III - "Estudos integradores", que devem respeitar "a diversidade nacional e a autonomia pedagógica das instituições" (BRASIL, 2015, p. 9).

Dessa forma, articulando a flexibilização curricular apontada pelo Parecer CNE/CES no 266/2011 e a relativa autonomia pedagógica permitida pela Resolução CNE/CP no 2/2015, os estudantes egressos do BHU e ingressos no curso de História solicitam aproveitamento de estudos referentes aos Núcleos I e II, contemplados por componentes curriculares optativos ainda durante o $1^{\circ}$ ciclo, ou seja, enquanto cursavam o BHU.

Dos 6 semestres ( 3 anos) cursados no $1^{\circ}$ ciclo do BHU, é possível ao estudante realizar o aproveitamento de 4 semestres ( 2 anos) de sua estrutura curricular para o $2^{\circ}$ ciclo, graças ao formato de flexibilização curricular, restando as componentes curriculares específicas do curso de História, principalmente laboratórios e estágios supervisionados, que devem ser cursados durante os 4 semestres ( 2 anos) específicos do $2^{\circ}$ ciclo de História. Dito de outra forma: o licenciando em História aproveita 2 anos de estudos cursados no BHU que serão somados aos 2 anos, específicos na licenciatura, alcançando, assim, os 4 anos de tempo mínimo exigido pelo artigo 13 da Resolução CNE/ $\mathrm{CP} \mathrm{n}^{\circ} 2 / 2015$, somando uma carga horária mínima de 3.345 horas entre os componentes descritas no PPC de História (Unilab, 2018).

A engenharia para integralização curricular do curso de $2^{\circ}$ ciclo, no entanto, vai muito além do somatório de carga horária das componentes curriculares. Um PPC, mais do que um documento oficial necessário ao funcionamento de qualquer unidade de ensino, é também importante documento que encerra em si não apenas informações técnicas, mas, sobretudo, preserva as memórias e as trajetórias de construção de um projeto coletivo que é a implementação de um curso. Com isso, afirmamos que ele também é uma importante fonte histórica para quem busca conhecer e refletir sobre as narrativas que subsidiaram e legitimaram a existência de um projeto que é, ao mesmo tempo, de natureza institucional e humana também, ou seja, que carrega em si as dimensões do "ser" e do "devir".

Contudo, entendemos o PPC também como "um território prático sobre o qual se pode discutir, investigar, mas, antes de tudo, sobre o qual se pode intervir" (Sacristan; Gomez 1998, p. 145), por isso trazemos o PPC do curso 
de Licenciatura de História como uma possível senda para acessar certo universo curricular cujo caráter inovador merece um olhar crítico e compreensivo com vistas a examinar seus possíveis avanços, mas também antever o quê de potencialidade e desafio também lhe constitui.

Avaliamos que o PPC, um importante documento histórico, expressa uma síntese e uma representação das vontades de saber e conhecer que determinado coletivo vislumbrou como projeto de educação a ser aplicado e, de algum modo, reconstruído na prática. Entendido como parcela, e não o todo, da investigação, esse documento principal que tem subsidiado nossas reflexões, na verdade, se conecta a outras dimensões, de natureza prática, tão importantes quanto o próprio documento oficial. A compreensão de currículo subjacente às nossas análises o considera "um processo social que se cria e passa a ser experiência através de múltiplos contextos que interagem entre si” (Sacristan; Gomez, 1998, p. 138), mais que mera "transposição" de conteúdos (teóricos, programáticos ou metodológicos) extraídos dos documentos oficiais para a prática. Desse modo, os documentos oficiais que norteiam os sistemas de ensino e suas unidades, como é o caso de um PPC, constituem pontos de apoio e de partida para a realização do trabalho docente e não mera camisa de força.

Cientes de que o currículo "não se mostra apenas em suas modelagens documentais - prescrições ou livros-texto - mas, na interação de todos os contextos práticos" (Sacristan; Gomez, 1998, p. 138), é que também incorporamos às nossas análises as nossas práticas docentes, cujo diapasão tem se conectado dialeticamente entre o documento e a ação. Ter participado da produção desse documento, hoje, nos permite, não apenas rever os passos dados rumo à efetivação do curso em si, mas também nos possibilita o lugar privilegiado de refletir sobre as memórias em que nós mesmos nos encontramos envolvidos como sujeitos, tendo o privilégio adicional de reexaminá-lo à luz das contradições apresentadas pela dimensão prática de sua reconstrução em sala de aula, por sua vez, tensionada pela interação com outros receptores que não aqueles oriundos de um corpo de especialistas já aclimatados ao universo e aos dialetos acadêmico-científico.

Assim, nesse exercício de auto-objetivação ${ }^{17}$ ao qual temos nos lançado, partimos das memórias sobre nossas práticas docentes para refletir sobre o curso, tendo por referência empírico-analítica nossa trajetória e nosso protagonismo sobre o próprio curso do qual temos participado desde a construção 
de seu PPC até suas seguidas atualizações decorrentes tanto das demandas de discentes que cursaram as turmas iniciais quanto de docentes do curso. Importa destacar que parcela dessas alterações ocorreu com a finalidade de contemplar conteúdos e abordagens relacionados aos direitos humanos, seja no sentido de avançar no campo específico dos Estudos de Gênero ou de consolidar uma formação antirracista em nosso currículo.

Desse modo, em 2017, foi criada e incorporada ao PPC de Licenciatura em História a disciplina "Gêneros e Sexualidades na História/75h":

Gêneros e Sexualidades na História (75h). Ementa: A genealogia dos estudos de gênero e sexualidade: trajetórias e debates. Gênero e Sexualidade como categorias de análise histórica. Gêneros e Sexualidades como campo de pesquisa na História: teorias, métodos e abordagens. Discutindo Gêneros e Sexualidades: femininos e masculinos na história. Para além dos binarismos: estudos sobre homo e transexualidades. A Teoria Queer e os Estudos Históricos. Os estudos de gênero e sexualidade no Brasil e em África. Gêneros e Sexualidades na escola de educação básica. (UNILAB, 2018, p. 122-123).

Esse componente veio a se somar às demais já presentes no PPC, mas que não possibilitavam o aprofundamento do debate acadêmico a partir dos estudos de gênero. Em interface direta com SDDH, cursada no $1^{\circ}$ ciclo formativo do curso, "Gêneros e sexualidades na História" tem possibilitado a discussão sobre o processo de invisibilização feminina no campo da produção historiográfica, tendo por ponto de partida as reflexões lançadas por Scott (1995) no seu já clássico artigo "Gênero: uma categoria útil de análise histórica", que suscita reflexões avançadas rumo à análise crítica de outras invisibilizações ocorridas na historiografia com base na hegemonia e no binarismo heteronormativos.

A experiência docente com essa disciplina tem nos mostrado o quanto, de fato, a afirmação dos direitos humanos em relação às identidades sexuais e de gênero persiste como discurso não realizado na prática. Com isso, "Gêneros e sexualidades na História” tem funcionado como suporte teórico-metodológico para estudantes interessados nessa temática com o objetivo de pesquisá-la, bem como, conforme relatos de alguns, representa importante "suporte de vida" para estudantes interessados na temática como elemento constitutivo de suas biografias. 
Realizar o debate nessa perspectiva implica, necessariamente, trazer questões que envolvem o chão concreto da vida de jovens que buscam na universidade um espaço de aquisição de conhecimento e diálogo e compreensão de si. A busca pelo lugar da autopercepção de si mesmo como sujeito de conhecimento se dá, passo a passo, com o desejo de compreender como as hierarquias sociais pautadas na diferença sexual foram se construindo tão forte e profundamente ao ponto de, para muitos de nossos estudantes, hoje, ser irreconhecível a sua gênese.

Como meio de sistematização dos debates em sala de aula, diferentes atividades são propostas e, entre elas, a elaboração de "memorial" permite a produção de melhores resultados por demandar que cada estudante atravesse suas experiências de vida com um dos textos explorados durante as aulas. Sendo a seleção do texto de livre escolha, devendo ser explorado a partir de conexões reais com momentos importantes experimentadas pelos próprios estudantes, seja pela vivência ocorrida de forma pessoal ou pela observação. A maioria das falas apresentadas, por vezes, assume contornos intimistas em tom autoral e na forma de narrativas-depoimentos e descrições-extravasamentos, geralmente acompanhadas da necessidade de que as reflexões coletivas providenciem uma análise teórica que permita explicações concatenadas para os processos de violações por eles rememorados. Em seus atravessamentos texto-vida, são irmãs, mães, vizinhas, amigas do trabalho ou da escola e primas que vão emergindo como personagens de episódios reais de invisibilização das violências e resistências traçadas cotidianamente. Os textos, de teoria-letra, se transformam em teoria-ação e uma segunda dimensão da disciplina é oferecida: a apropriação da carga horária destinada à Prática como Componente Curricular (PCC) como projeto a ser executado nas escolas a partir do estudo prévio da legislação principal que norteia a abordagem dessa temática na educação básica.

Após leitura e discussão em equipes da parte sobre orientação sexual dos Parâmetros Curriculares Nacionais (Brasil, 1998), além de artigos acadêmicos específicos sobre essa temática na escola, os estudantes são instados a visitar e desenvolver diferentes atividades em escolas públicas do Maciço de Baturité. Entre as atividades, são realizadas desde entrevistas com o núcleo gestor e as equipes docentes até mesmo a proposição de projetos que possam contribuir tanto para a desmistificação da temática como "ideologia de gênero" quanto para a abordagem pela escola de forma qualificada e produtiva dos estudos de 
gênero. Já a abordagem dos direitos humanos a partir de uma formação antirracista é mais explícita no PPC e tem na sua concepção transnacional referenciada desde experiências afrodiaspóricas à expectativa de contemplar as necessidades de estudantes brasileiros e africanos, além do próprio corpo docente do curso, cuja composição valoriza a diversidade.

Atualmente, somos 18 docentes, todos com doutorado, entre os quais três são internacionais, sendo uma bissau-guineense, um alemão e uma argentina. Vale destacar que apenas dois apresentam formação acadêmica em pós-graduação concluída no Ceará, sendo que o perfil acadêmico dos demais é bastante variado, predominando, no entanto, Rio de Janeiro, São Paulo, Minas Gerais e Bahia como epicentro de suas formações acadêmicas em pós-graduação. Quanto aos critérios de cor e gênero, temos 11 não negros e 7 negros; dos 11 não negros, 4 são mulheres, e, dos 7 negros, 2 são mulheres.

Apontar o perfil docente é importante, pois ele nos permite pensar que parte do currículo transnacional referenciado nas experiências afrodiaspóricas do curso de História é tributário não apenas da perspectiva institucional dos atos normativos da universidade, mas também expressão das sensibilidades e dos afetos construídos por seus sujeitos quando em processos formativos fora de suas relativas zonas de conforto. Compreender a diferença pela experiência concreta em que nos colocamos na condição de "diferentes" nos possibilita olhar as relações humanas pelas lentes da empatia e da alteridade. Dito de outro modo: o fato de não termos um corpo docente integralmente formado endogenamente nos privilegiou com o olhar mais empático e cuidadoso para a diversidade de modo a contemplá-la em sua concretude humana e não apenas na forma de narrativas oficiais. O perfil dos docentes que compõem nosso curso de História, aliado à missão institucional da Unilab, permitiram a construção de um currículo inovador a partir de uma estrutura afrorreferenciada, advindo daí seu caráter transnacional ao buscar incluir conteúdos e abordagens referentes aos países parceiros da CPLP.

No âmbito nacional, a inclusão, no currículo dos cursos de História, de temas relacionados à história e cultura africana e afro-brasileira é relativamente recente, tendo sido iniciada a partir da aprovação da Lei $n^{\circ} 10.639 / 2003$ (BRASIL, 2003), da qual, de certa forma, a Unilab é uma de suas repercussões; no entanto, é pertinente assinalar que os currículos das universidades brasileiras, praticamente, continuaram a ignorar os conteúdos afrodiaspóricos. A Uni- 
versidade Federal do Ceará (UFC), por exemplo, até 2002, época de nossa formação em seu curso de graduação em História, não possuía nenhuma componente curricular abordando a história da África, sendo esse contexto não muito distinto em outras instituições de ensino superior responsáveis pelo processo de formação de professores para a educação básica, como demonstrou Ricardo Oriá ao analisar os desafios para implementação da Lei no 10.639/2003:

Um dos gargalos do sistema educacional brasileiro reside na qualificação do corpo docente, sobretudo os que exercem o magistério nas séries iniciais do ensino fundamental. Esses professores, na sua grande maioria de formação polivalente e sem curso superior, precisam estar habilitados a trabalhar com essa nova temática curricular. Sugere-se, para tanto, um esforço por parte dos órgãos governamentais ligados à área de promoção da igualdade racial, no sentido de oferecer, em parceria com as instâncias educacionais, cursos de extensão sobre a história da África e de cultura afro-brasileira, bem como a publicação de material didático-pedagógico que possa dar suporte técnico a atuação desses docentes no desenvolvimento do processo ensino-aprendizagem. (FERNANDES, 2005, p. 384).

Para superar esse déficit em relação à temática da história e cultura africana e afro-brasileira na educação básica e superior e valorizar uma formação antirracista, ainda no $1^{\circ}$ ciclo trabalhamos os conteúdos das componentes "SDDH", "Identidade e Poder" e "Território e Poder", responsáveis pelo diálogo com a Lei no 10.639/2003 (BRASIL, 2003). Já no $2^{\circ}$ ciclo, nas componentes específicas do curso de Licenciatura em História, além da disciplina "História e Historiografia da África/90h", outras unidades curriculares trazem em seu foco a perspectiva africana, como é o caso do componente "Antiguidade Africana, Médio-Oriental e Mediterrânea/90h”, em que ganham relevo os debates sobre o desenvolvimento de tecnologias e civilizações na África, muito anterior às civilizações greco-romana, tradicionalmente enfocadas pela conhecida disciplina de "História Antiga" nos currículos convencionais. Até mesmo a abordagem dos processos históricos situados no contexto medieval tão intrínseco à própria emergência do conceito de Europa é tratada com outro foco, privilegiando a expansão do islamismo no Norte da África e sua relação com as sociedades mediterrâneas europeias, que se constituem como temáticas problematizadas na componente curricular obrigatória "O mundo Islâmico e o Medievo Europeu/90h". 
Além dos esforços de realizar uma crítica a contrapelo da história eurocêntrica, procurando enfatizar as contribuições e a importância das civilizações africanas para além da associação quase exclusiva à escravidão negra, tão comum em currículos de outros cursos de História, mesmo após a Lei $\mathrm{n}^{\circ}$ $10.639 / 2003$, buscamos proporcionar aos estudantes, brasileiros e internacionais, um currículo transnacional referenciado nas experiências afrodiaspóricas por componentes voltados aos conteúdos pedagógicos, como em "Organização da Educação Básica no Brasil e nos Países da Integração/60h" e em "Didática nos Países da Integração/60h”, que exploram conteúdos específicos da educação brasileira e, também, dos países africanos da CPLP mais o Timor-Leste. Constam, ainda, componentes optativos dialogando com a história nacional de Guiné-Bissau, Cabo-Verde, Angola, São Tomé e Príncipe, Timor Leste e Moçambique, todas com 75 horas, e possíveis de serem cursadas no $1^{\circ}$ ou $2^{\circ}$ ciclo. Ainda merecem destaque as componentes "História e o Mundo Colonial/90h" e "História do Racismo e do Antirracismo no Mundo Atlântico/75h" (Unilab, 2018), unidades curriculares que permitem abordar as epistemologias decoloniais e antirracistas.

Os conteúdos voltados à diáspora africana também são abordados na componente "História e Historiografia da América/90h", bem como nas quatro componentes curriculares de História do Brasil, cada uma delas com 75 horas (Unilab, 2018). Nesse caso, por relevante, citamos o exemplo dos debates a respeito do processo da autonomia política do Brasil, em 1822, ao tomar como temática geradora o 2 de julho na Bahia, isto é, o movimento de Independência da Bahia, e a atuação dos negros nas lutas pela independência a partir das contribuições de Hendrik Kraay (2002), como modo de destacar a presença de africanos e afro-brasileiros no processo de construção da cidadania, fugindo da abordagem tradicional que, ao tratar a chamada "independência do Brasil”, destaca somente a participação das elites políticas e intelectuais do circuito luso-brasileiro.

\section{Conclusão: "Porta QUe NÃo VAi FEChar nUNCA MAIs"}

Com essa afirmação, uma estudante expressou o que a componente curricular "Sociedades, Diferenças e Direitos Humanos nos Espaços Lusófonos" representou para ela, no ano de 2017, cuja importância, em suas palavras, não 
repousava apenas no fato de ter conquistado o seu ingresso em uma universidade pública federal. À supracitada leitura, a estudante adicionou a compreensão de que o próprio ingresso implicou num "duro e sofrido processo" de ter que olhar, "com outros olhos", para a sua própria biografia agora ladeada pelos processos históricos nacionais e continentais, finalmente, entendendo que ela só adquiriu sentido ao passo que a compreendeu como "entrelaçada" com a do próprio país.

Mesmo com risco de cair em alguma compreensão determinista, a estudante expressou naquele momento, mês de encerramento das atividades letivas e, portanto, momento de autoavaliação e avaliação da disciplina, o que ela entendia como tendo sido um exercício de catarse epistemológica

Hoje compreendo, $[\ldots]$ que realmente eu sou o que este país é. A história deste país está em mim, tá entendendo?! Eu sou o que este país é... pobreza, exploração, racismo, homofobia, violência, sabe?! É triste, mas, ao mesmo tempo, que dói, é uma dor que fica pedindo pra eu continuar, pra eu olhar pra trás e dizer pra mim, pra minha mãe 'Chega! Tá bom! Vamu fazer diferente. Vamu tentar ser diferente'. Antes eu já queria isso, mas não sabia como. E, hoje, acho que não sabia 'como', porque não entendia como que chegamos até aqui, por que somos como somos e o que somos. Agora não. Agora eu sei. Não sei tudo, claro. Mas sei muito mais do que sabia antes. E continuando, vou saber mais. Saber de onde veio minha pobreza. Entender que não sou pobre por acaso ou porque deus quis. Saber o porquê de sendo mulher, ser cobrada por tantas coisas que meus irmãos, por exemplo, não são. Entender por que pude estudar e meus irmãos, mais velhos e mais pretos que eu, não. Hoje entendo. E dói. Dói, mas é pra doer mesmo porque é um aprendizado, sabe... Tão profundo... e é por isso que acho que dói. Na escola, não tive isso. Não pude ter. Aqui eu tô me encontrando no sentido de saber mesmo quem sou e por que sou. E por isso que acho que essa é uma porta que não vai fechar nunca $[\ldots]$ Nunca mais. ${ }^{18}$

Estar concluindo a referida disciplina, segundo a jovem, lhe garantiu uma compreensão mais profunda do que era estar ali, numa sala de aula de uma universidade construída numa região periférica do país, em convívio com tantos outros jovens, autores de experiências também marcadas pelas estruturas de dominação que conjugam o mundo globalizado em termos bastante assemelhados porque pautados nas opressões de raça, gênero e classe. Segundo 
seus relatos, a própria palavra "periférica" também passou a assumir outras conotações, entre as quais “empoderamento" e "orgulho" de si mesma e de sua trajetória, até então, vista senão com certo desprezo, ao menos incompreensão, do que pode significar ser marginalizada.

A fala da discente em questão, na época, nos remeteu à crítica lançada por Boaventura dos Santos às narrativas dos direitos humanos que, segundo ele, têm existido a partir de uma inexorável contradição, pois, apesar de hegemônicas, convivem com o que ele chama de "realidade perturbadora", qual seja a de que "a grande maioria da população mundial não é sujeito de direitos humanos. É objeto de discurso de direitos humanos" (SANTOS, 2013, p. 15). Desse modo, as narrativas dos direitos humanos correm o risco de que, ao invés de se concretizarem no mundo real, se restrinjam como linguagem de dignidade humana meramente no campo da retórica e, assim, se reproduzam muito mais como discurso do que como prática.

Diante de tal infortúnio, Santos questiona se, em cenário tão desolador, ainda são possíveis outros direitos humanos, mais eficazes no combate às opressões e dominações decorrentes do colonialismo e do capitalismo. Sem demora, apesar das críticas lançadas, o autor responde, renovando seu compromisso com a afirmação dos direitos humanos, que "nunca como hoje foi tão importante não desperdiçar ideias e práticas de resistência. [...] só reconhecendo as debilidades reais dos direitos humanos é possível construir a partir deles, mas também para além deles, ideias e práticas fortes de resistência" (SANTOS, 2013, p. 98).

Com o entendimento de que a Unilab se constitui num repertório diverso de "ideias e práticas fortes de resistência", consideramos que os cursos de Bacharelado em Humanidades ( $1^{\circ}$ ciclo) e Licenciatura em História ( $2^{\circ}$ ciclo) têm contribuído no âmbito da educação superior com os esforços de ampliação de uma cidadania antipatriarcal e antirracista na formação de futuros professores da educação básica no Brasil e nos países parceiros da Unilab e, portanto, irradiando a consolidação de direitos humanos e sociais. Tal perspectiva foi reconhecida pelo próprio Instituto Nacional de Estudos e Pesquisas Educacionais Anísio Teixeira (Inep), vinculado ao Ministério da Educação, que, em abril de 2018, após visita in loco, atribuiu conceito máximo ao processo de reconhecimento do curso de Licenciatura em História da Unilab no Ceará ${ }^{19}$, o que nos leva a observar que a jornada do curso vem sendo reconhecida, apesar de todos 
os desafios e as adversidades, seja do ponto de vista da legislação e dos organismos reguladores da educação superior no Brasil ou da agenda conservadora e subalternizante imposta no cenário nacional desde 2016.

\section{REFERÊNCIAS}

ADICHIE, Chimamanda Ngozi. Sejamos todos feministas. São Paulo: Companhia das Letras, 2015.

BOURDIEU, Pierre. Homo Academicus. California: Stanford University Press, 1988.

BRASIL. Ministério da Educação. Secretaria de Educação Fundamental. Parâmetros curriculares nacionais: terceiro e quarto ciclos do ensino fundamental. Temas transversais. Brasília: MEC/SEF, 1998. Disponível em: http://portal.mec.gov.br/ seb/arquivos/pdf/ttransversais.pdf. Acesso em 31 jul. 2020.

BRASIL. Lei no 10.172, de 9 de janeiro de 2001. Aprova o Plano Nacional de Educação e dá outras providências. Diário Oficial da União, Brasília, DF, 10 jan. 2001. Disponível em: http://www.planalto.gov.br/ccivil_03/leis/leis_2001/110172.htm. Acesso em: 15 jul. 2020.

BRASIL. Lei no 10.639, de 9 de janeiro de 2003. Altera a Lei no 9.394, de 20 de dezembro de 1996, que estabelece as diretrizes e bases da educação nacional, para incluir no currículo oficial da Rede de Ensino a obrigatoriedade da temática "História e Cultura Afro-Brasileira”, e dá outras providências. Diário Oficial da União, Brasília, DF, 10 jan. 2003. Disponível em: http://www.planalto.gov.br/ccivil_03/ leis/2003/110.639.htm. Acesso em: 15 jul. 200.

BRASIL. Decreto no 6.096, de 24 de abril de 2007. Institui o Programa de Apoio a Planos de Reestruturação e Expansão das Universidades Federais - REUNI. Diário Oficial da União, Brasília, DF, 25 abr. 2007. Disponível em: http://www.planalto. gov.br/ccivil_03/_ato2007-2010/2007/decreto/d6096.htm. Acesso em: 15 jul. 2020.

BRASIL. Lei no 11.645, de 10 de março de 2008. Altera a Lei no 9.394, de 20 de dezembro de 1996, modificada pela Lei no 10.639, de 9 de janeiro de 2003, que estabelece as diretrizes e bases da educação nacional, para incluir no currículo oficial da rede de ensino a obrigatoriedade da temática "História e Cultura Afro-Brasileira e Indígena”. Diário Oficial da União, Brasília, DF, 11 mar. 2008. Disponível em: http:// www.planalto.gov.br/ccivil_03/_Ato2007-2010/2008/Lei/L11645.htm. Acesso em: 15 jul. 200.

BRASIL. Lei no 12.289, de 20 de julho de 2010. Dispõe sobre a criação da Universidade da Integração Internacional da Lusofonia Afro-Brasileira - UNILAB e dá outras providências. Diário Oficial da União, Brasília, DF, 21 jul. 2010a. Disponível em: http://www.planalto.gov.br/ccivil_03/_ato2007-2010/2010/lei/L12289.htm. Acesso em: 20 jun. 2020. 
BRASIL. Lei no 12.288, de 20 de julho de 2010. Institui o Estatuto da Igualdade Racial; altera as Leis ${ }^{\text {os }} 7.716$, de 5 de janeiro de 1989, 9.029, de 13 de abril de 1995, 7.347, de 24 de julho de 1985, e 10.778, de 24 de novembro de 2003. Diário Oficial da União, Brasília, DF, 21 jul. 2010b. Disponível em: http://www.planalto.gov.br/ccivil_03/_Ato2007-2010/2010/Lei/L12288.htm. Acesso em: 20 jun. 2020.

BRASIL. Decreto n ${ }^{\circ}$ 7.234, de 19 de julho de 2010. Dispõe sobre o Programa Nacional de Assistência Estudantil - PNAES. Diário Oficial da União, Brasília, DF, 20 jul. 2010c. Disponível em: http://www.planalto.gov.br/ccivil_03/_ato2007-2010/2010/ decreto/d7234.htm. Acesso em: 15 jul. 2020.

BRASIL. Parecer CNE/CES no 266, de 6 de julho de 2011. Referenciais orientadores para os Bacharelados Interdisciplinares e Similares das Universidades Federais. Diário Oficial da União, Brasília, DF, 14 out. 2011. Disponível em: http://portal. mec.gov.br/index.php?option $=$ com_docman \&view $=$ download $\&$ alias $=8907$ -pces266-11\&category_slug=setembro-2011-pdf\&Itemid=30192. Acesso em: 20 jun. 2020.

BRASIL. Parecer CNE/CP no 8, de 6 de março de 2012. Diretrizes Nacionais para a Educação em Direitos Humanos. Diário Oficial da União, Brasília, DF, 30 maio 2012. Disponível em: http://portal.mec.gov.br/index.php?option=com docman\&view=download\&alias=10389-pcp008-12-pdf\&category_slug=marco2012-pdf\&Itemid=30192. Acesso em: 15 jul. 2020.

BRASIL. Resolução CNE/CP n 2, de 1 de julho de 2015. Define as Diretrizes Curriculares Nacionais para a formação inicial em nível superior (cursos de licenciatura, cursos de formação pedagógica para graduados e cursos de segunda licenciatura) e para a formação continuada. Diário Oficial da União, Brasília, DF, 1 jul. 2015. Disponível em: http://portal.mec.gov.br/docman/agosto-2017-pdf/70431-res-cnecp-002-03072015-pdf/file. Acesso em: 20 jun. 2020.

BRASIL. Cursos de História e Sociologia têm excelente avaliação pelo MEC. Unilab Notícias, Redenção, 19 abr. 2018. Disponível em: http://unilab.edu.br/noticias/2018/04/19/cursos-de-historia-e-sociologia-tem-excelente-avaliacao-pelo-mec/. Acesso em: 17 jul. 2020

CARNEIRO, Sueli. Racismo, sexismo e desigualdade no Brasil. São Paulo: Selo Negro, 2011.

FERNANDES, José Ricardo Oriá. Ensino de história e diversidade cultural: desafios e possibilidades. Cadernos CEDES, Campinas, v. 25, n. 67, p. 378-388, set./dez. 2005. Disponível em: https://www.scielo.br/pdf/ccedes/v25n67/a09v2567.pdf. Acesso em: 10 jul. 2020.

FREIRE, Paulo. Pedagogia do oprimido. Rio de Janeiro: Paz e Terra, 2016.

HUNT, Lynn. A invenção dos direitos humanos: uma história. São Paulo: Companhia das Letras, 2009. 
IPECE. Perfil das Regiões de Planejamento - Maciço de Baturité/2017. Fortaleza: IPECE, 2017. Disponível em: http://www2.ipece.ce.gov.br/estatistica/perfil_regional/2017/PR_Macico_de_Baturite_2017.pdf. Acesso em: 20 jun. 2020.

KRAAY, Hendrik. "Em outra coisa não falavam pardos, cabras e crioulos": o "recrutamento" de escravos na Guerra da Independência na Bahia. Revista Brasileira de História, São Paulo, v. 22, n. 43, p. 109-126, 2002. Disponível em: https://www. scielo.br/pdf/rbh/v22n43/10913.pdf. Acesso em: 12 jul. 2020.

MBAYA, Etienne-Richard. Gênese, evolução e universalidade dos direitos humanos frente à diversidade de culturas. Estudos Avançados, São Paulo v. 11, n. 30, p. 1741, ago. 1997. Disponível em: https://www.scielo.br/pdf/ea/v11n30/v11n30a03. pdf. Acesso em: 31 jul. 2020.

MOTT, Luiz. Raízes históricas da homossexualidade no Atlântico lusófono negro. Afro-Ásia, Salvador, n. 33, p. 9-33, 2005. Disponível em: https://portalseer.ufba.br/ index.php/afroasia/article/view/21099/13982. Acesso em 31 jul. 2020.

MUNANGA, Kabengele. Negritude: usos e sentidos. Belo Horizonte: Autêntica, 2012.

ONU. Declaração Universal dos Direitos Humanos. Genebra: ONU, 1948. Disponível em: https://www.ohchr.org/EN/UDHR/Documents/UDHR_Translations/por.pdf. Acesso em: 15 jul. 2020.

RIBEIRO, Darcy. O povo brasileiro: a formação e o sentido de Brasil. São Paulo: Companhia das Letras, 2005.

SACRISTAN, José Gimenez; GOMEZ, Ángel I. Pérez. Compreender e transformar o ensino. Tradução Ernani F. da Fonseca Rosa e Maria da Graça Souza Horn. Porto Alegre: Artmed, 1998.

SALES, Edriene Cristine da Silva Santos et al. O programa de apoio à planos de Reestruturação e Expansão das Universidades Federais (REUNI): uma análise de seu processo de avaliação. Avaliação, Campinas, Sorocaba, v. 24, n. 3, p. 658-679, dez. 2019. Disponível em: https://www.scielo.br/pdf/aval/v24n3/1982-5765aval-24-03-658.pdf. Acesso em: 30 jun. 2020.

SANTOS, Boaventura de Sousa. Se Deus fosse um ativista dos direitos humanos. São Paulo: Cortez, 2013.

SCOTT, Joan. Gênero: uma categoria útil de análise histórica. Educação \& Realidade, Porto Alegre, v. 20, n. 2, p. 71-99, 1995. Disponível em: https://seer.ufrgs.br/educacaoerealidade/article/view/71721/40667. Acesso em: 30 jul. 2020.

SILVA, Maurício. Universidade Popular no Brasil e relações étnico-raciais: o caso da Universidade da Integração Internacional da Lusofonia Afro-Brasileira (Unilab). Revista Internacional de Educação Superior, Campinas, v. 4, n. 1, p. 112-129, abr./ jun. 2018. Disponível em: https://periodicos.sbu.unicamp.br/ojs/index.php/riesup/article/view/8650726/16890. Acesso em: 9 jul. 2020. 
SILVA, Tomaz Tadeu da. Documentos de identidade: uma introdução às teorias do currículo. Belo Horizonte: Autêntica, 2010.

UNILAB. Projeto Pedagógico do Curso de Licenciatura em História. Acarape: Unilab, 2018. Disponível em: http://historia.ihl.unilab.edu.br/wp-content/uploads/2018/08/PPC.-V7.-Hist\%C3\%B3ria.-Semestral.24.-Mar\%C3\%A7o.-2018.pdf. Acesso em: 17 jul. 2020.

UNILAB. Unilab em números. Painel de Ensino. Graduação. Acarape: Unilab, 2019. Disponível em: https://app.powerbi.com. Disponível em: https://app.powerbi.com/ view?r=eyJrIjoiNTkzZjY2MWQtNjMzNS00MjkzLWI4YTAtOGJjY2NmNjdmNzI 1 Iiwid CI6Ijkw MjlkZ GNlLW F m M T It N D JiZS0 4 M D M 3 LT U 4 MzEzZTRkYzVkMSJ9. Acesso em: 20 jul. 2020

\section{NOTAS}

${ }^{1}$ De fato, Hunt se refere especificamente a apenas homens, oriundos das elites políticas e econômicas da época, destacando, nomeadamente, as ações de Thomas Jefferson, nos Estados Unidos, e à ação de Lafayette, na França, como integrando o grupo de "fundadores", responsáveis por estruturar e redigir as declarações de direitos humanos da época (HUNT, 2009, p. 17).

${ }^{2}$ Ao longo de todo o artigo, ao utilizarmos o conceito de "sociedades não hegemônicas", dialogamos com Santos (2013) e, portanto, nos referimos às sociedades formadas por "povos que entraram na zona de contato com a modernidade ocidental" e que "fizeram-no em condições de inferioridade forçada, como foi tipicamente o caso do colonialismo. Muitos foram forçados a abandonar as concepções que os tinham guiado antes de chegar à zona de contato, outros adotaram de modo mais ou menos voluntário os novos princípios ou apropriaram-se deles conferindo-lhes novos sentidos" (Santos, 2013, p. 79). Para este artigo, em específico, a expressão sociedades não hegemônicas corresponde àquelas sociedades construídas pelas populações afro-indígenas e africanas, marcadas por processos de diáspora forçada.

${ }^{3}$ No mesmo dia, 20 de julho de 2010, foram aprovadas a Lei no 12.288/2010 (Brasil, 2010b), que instituiu o Estatuto da Igualdade Racial, e a Lei no 12.289/2010 (Brasil, 2010a), que criou a Unilab. Talvez este ato legislativo seja o de maior simbolismo para a Unilab, mas não é o único. Entre tantas outras marcas simbólicas que a Unilab traz em sua história, destacamos duas cuja carga representativa é bastante expressiva do que ela é, ou ao menos almeja ser, como instituição de educação superior no país. Logo após o seu processo de implantação para funcionamento imediato ter sido concluído, foi feita a indicação da professora e pesquisadora Nilma Lino Gomes, oriunda da Universidade Federal de Minas Gerais (UFMG), como reitora da Unilab, cuja gestão se estendeu de 2012 até final de 2014, quando foi convidada a assumir a Secretaria Nacional de Políticas de Promoção da Igualdade Racial (Seppir). A professora Nilma, com isso, se tornou a primeira mulher negra a 
assumir um cargo de tamanha importância na educação superior brasileira. Após sua saída, substituiu-lhe o professor Luíz Thomaz, também oriundo da UFMG, onde já havia se consagrado como o primeiro reitor negro de uma universidade pública federal brasileira.

${ }^{4} \mathrm{O}$ público nacional atendido pela Unilab no Ceará é formado por estudantes oriundos de municípios adjacentes, por exemplo, Guaiúba e Pacatuba, mas também de Fortaleza, capital do Estado.

${ }^{5}$ Aratuba, Aracoiaba, Acarape, Barreira, Baturité, Capistrano, Guaramiranga, Itapiúna, Mulungu, Ocara, Pacoti, Palmácia e Redenção. A Unilab atende diretamente os municípios de Redenção, onde estão localizados os campi de Liberdade e das Auroras, e o de Acarape, onde está situada a unidade acadêmica dos Palmares. Imediatamente adjacente à Acarape, temos o município de Barreira, que também é fortemente atendido pela Unilab. Todos os demais municípios também se encontram no arco de atendimento e acolhimento de suas populações pela universidade, devido à relativa proximidade entre os municípios do Maciço do Baturité.

${ }^{6}$ Além dos empregos nas administrações públicas municipais, parte da população se emprega no pequeno e médio comércio, bem como nas fazendas locais que ainda conseguem firmar presença na economia do Ceará. Os municípios de Baturité e Guaramiranga, em razão de possuírem clima mais ameno, também se destacam pela atração turística que exercem internamente na região, atraindo, sobretudo, turistas de Fortaleza que costumam despender seus finais de semana lá, fugindo do calor praieiro da capital. Para informações detalhadas sobre as particularidades do Maciço de Baturité, ver Ipece (2017).

${ }^{7}$ Cada ciclo representa um grau acadêmico específico com diplomação. Dessa forma, ao concluir os dois ciclos, o estudante recebe duas diplomações. Conforme o Parecer CNE/ CES n 266/2011: "Cabe ressaltar que o termo ciclos utilizado no contexto dos Bacharelados Interdisciplinares não tem relação com ciclos básico e profissional instituídos pela Lei 5.540/68. No caso dos Bacharelados Interdisciplinares o termo ciclo é utilizado para fazer referência a uma etapa completa de formação que conduz a diploma e possui objetivos formativos bem definidos e perfil de egressos especificado" (Brasil, 2011). Assim, aqueles que acompanham o fluxo curricular proposto, com 3 anos, recebem a diplomação do Bacharelado em Humanidades e, com 5 anos, a contar de seu ingresso pelo SiSU, podem obter a diplomação na Licenciatura em História, ou uma das outras opções de $2^{\circ}$ ciclo (Antropologia, Sociologia ou Pedagogia).

${ }^{8}$ Ao contrário das demais universidades federais brasileiras participantes do Programa Estudante Convênio de Graduação (PEC-G), vinculado ao Ministério de Relações Exteriores (MRE), e em razão de sua missão institucional maior prevista na Lei $n^{\circ} 12.289 / 2010$, a Unilab nasce em acordo de cooperação apenas com os países lusófonos do continente africano e o Timor-Leste, que permitem seus estudantes egressos de seus sistemas de educação básica a dar continuidade aos seus trajetos formativos na Unilab. Das vagas reservadas e ofertadas para estudantes internacionais através do PSEE, aquelas não ocupadas são redirecionadas para candidatos brasileiros. 
${ }^{9}$ O Pnaes (2010c) foi instituído em 19 de julho de 2010 pelo Decreto no 7.234 (Brasil, 2010c), assinado pelo então presidente Luiz Inácio Lula da Silva.

${ }^{10}$ Instituído em 24 de abril de 2007 pelo Decreto nº 6.096 (Brasil, 2007), assinado pelo então presidente Luiz Inácio Lula da Silva, a REUNI foi aprovada em atendimento à Lei $\mathrm{n}^{\circ}$ 10.172, de 09 de janeiro de 2001 (Brasil, 2001), que aprovou o Plano Nacional de Educação (PNE), cujas metas previam a expansão da oferta de educação superior no Brasil.

${ }^{11}$ Nos termos de Silva (2018, p. 114), "o conceito de universidade popular aqui empregado aproxima-se daquele forjado, num primeiro momento, no contexto do Fórum Social Mundial e que apresenta como um de seus principais fundamentos a assunção de uma prática que se destina à produção de um conhecimento contra-hegemônico, como resistência à globalização neoliberal; segundo, a observação dos pressupostos e dos desdobramentos direta ou indiretamente relacionadas à Lei 10.639, de 2003 (Brasil, 2003), que define a obrigatoriedade do ensino de história e cultura africana e afro-brasileira nos ensinos fundamental e médio".

${ }^{12}$ Em julho de 2018, houve o desmembramento do Instituto de Humanidades e Letras (IHL), que, no Ceará, deu origem a duas novas unidades acadêmicas: os cursos de Bacharelado em Humanidades e Antropologia e as Licenciaturas em História, Sociologia e Pedagogia passaram a integrar o Instituto de Humanidades (IH), enquanto os cursos de Licenciatura em Letras-Língua Portuguesa e Letras-Língua Inglesa passaram a integrar o Instituto de Linguagens e Literaturas (ILL).

${ }^{13}$ No $1^{\circ}$ ciclo, o Bacharelado em Humanidades (BHU) possui uma carga horária mínima de 2.400 horas integralizadas em 3 anos; no $2^{\circ}$ ciclo, por sua vez, o Curso de Licenciatura em História tem a carga horária total de 3.345 horas. Graças ao mecanismo de flexibilização e formação em ciclos, parte da carga horária do BHU é aproveitada no $2^{\circ}$ ciclo, permitindo a conclusão dos dois ciclos/cursos em 5 anos, período máximo permitido aos estudantes para acesso aos auxílios financeiros disponíveis pelo PNAES.

${ }^{14}$ Além do Parecer CNE/CES no 266/2011 (Brasil, 2011), que homologa os Referenciais Orientadores para Bacharelados Interdisciplinares e Similares nas Universidades Federais, também nos referimos, especificamente, ao Parecer CNE/CP no 8/2012 (Brasil, 2012), que homologa as Diretrizes Nacionais para a Educação em Direitos Humanos, ao Plano Nacional de Educação em Direitos Humanos, bem como à Lei no $10.639 / 2003$ (Brasil, 2003) e à Lei no 11.645/2008 (Brasil, 2008), que aprovam, respectivamente, a inclusão, no currículo oficial da rede de ensino, da obrigatoriedade das temáticas "História e Cultura Afro-Brasileira" e "História e Cultura Afro-Brasileira e Indígena".

${ }^{15}$ Por "contra-hegemônico", entendemos os processos decorrentes das lutas contra a opressão neoliberal, capitalista e colonialista, pautadas no combate das estruturas de dominação patriarcal e étnico-racial. Refere-se, portanto, às práticas de resistência contra as desigualdades sociais, econômicas, políticas e culturais que promovem a atualização da discriminação e da dominação das populações sobreviventes e resistentes ao colonialismo (Santos, 2013). 
${ }^{16}$ Após estudos sobre o entorno geográfico e o perfil das comunidades habitantes da região onde a universidade está instalada, admitiu-se, à época, que, para fins de qualificação do corpo docente local que atende às escolas municipais e estaduais do Maciço de Baturité, o IHL deveria ofertar cursos cujos campos de saber tivessem ressonância e representação nas escolas na forma de disciplinas componentes do currículo dos ensinos fundamental e médio. Logo, foi constatado que, dentre esses campos de saber, o de História representava uma demanda importante para as comunidades locais.

${ }^{17}$ Pierre Bourdieu, no prefácio à edição inglesa de sua obra Homo Academicus, exorta à prática da auto-objetivação como um inescapável exercício metodológico para quem se interessa por se aprofundar nas camadas mais densas que constitui determinado campo de estudos, sendo que, segundo o autor, "não se pode evitar objetivar o sujeito objetivante" (Bourdieu, 1998, p. xii). Para atenuar os possíveis riscos de se imiscuir em abordagens autoindulgentes e, portanto, complacentes, enveredando-se por uma perspectiva meramente narrativo-descritiva, o mesmo Bourdieu entende que para isso é preciso inverter a prática etnológica de "domesticar o exótico" (original: "domesticate the exotic") e aderir ao procedimento de exotizar o doméstico (original: "exoticize the domestic") (Bourdieu, 1988, p. xi-xii).

${ }^{18}$ Entrevista concedida por uma discente brasileira, em 12 de dezembro de 2017, durante o processo de autoavaliação do componente curricular "Sociedades, Diferenças e Direitos Humanos nos Espaços Lusófonos".

${ }^{19}$ Conforme notícia publicada no portal institucional da Unilab que deu publicidade ao Relatório do Processo de Reconhecimento do curso de Licenciatura em História (Brasil, 2018).

Artigo recebido em 31 de julho de 2020. Aprovado em 16 de setembro de 2020. 